\title{
An Innovative Curriculum Development Experience: Emergency Medical Dispatch Role in the Healthcare Transformation Vision of Saudi Arabia
}

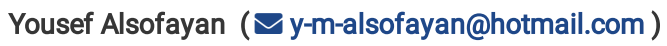

Saudi Red Crescent Authority

Kharsan Almakhalas

Saudi Red Crescent Authority

Abdullah Alabdali

King Saud bin Abdulaziz University for Health Sciences

Mohammed Arafat

Medical Referrals Center, Ministry of Health

\section{Nawfal Aljerian}

King Saud bin Abdulaziz University for Health Sciences

Ameera Cluntun

Health Academy, Saudi Commission for Health Specialties

Waad Alshammari

Health Academy, Saudi Commission for Health Specialties

Salman Alharthi

Saudi Red Crescent Authority

Fahad Alhajjaj

College of Medicine and Medical Sciences, Qassim University

Jalal Alowais

College of Medicine, Imam Mohammad Ibn Saud Islamic University

Sami Alsolamy

Health Academy, Saudi Commission for Health Specialties

Bandr Mzahim

Department of Disaster and Emergency Medicine, King Fahad Medical City

Abdulrahman Sabbagh

Emergency Medicine Administration, King Fahad Medical City

\section{Research Article}

Keywords: Dispatch, Emergency Medical Dispatch, Curriculum, Curriculum Development, Saudi Arabia, Healthcare Transformation, Vision 2030

Posted Date: November 30th, 2021

DOI: https://doi.org/10.21203/rs.3.rs-1111612/v1

License: (c) (i) This work is licensed under a Creative Commons Attribution 4.0 International License. Read Full License 


\section{Abstract}

\section{Background}

Healthcare medical dispatch systems play a fundamental role in the daily operations of prehospital services. This includes facilitating the interpretation of various dispatch-related systems, receiving incident calls, categorizing cases, guiding proper resources deployment, and providing proper instructions before the arrival of healthcare providers. Considering the Kingdom of Saudi Arabia's (KSA's) health sector transformation plan as part of Vision 2030, developing an Emergency Medical Dispatch (EMD) Program as part of essential prehospital services will allow rapid and competent healthcare delivery. In this study, our purpose is to describe the curriculum development of the EMD Program to improve the training of dispatchers and to share the experience in the interest of better prehospital dispatch systems.

\section{Methods}

A selected group of education experts and academics in emergency medical services dispatch were assigned to develop an EMD curriculum over six months. This study aims to describe the approach followed in developing an innovative EMD Program to share the experience and ultimately standardize dispatchrelated training programs. The data of this study was collected by reviewing approved documents of the EMD Program including program curriculum, syllabus, logbook, and exam blueprint after approval letters received from the Health Academy, Saudi Commission for Health Specialties.

\section{Results}

The development of the EMD program utilized a consecutive mixed approach staring with a competency-based with backward design method to ensure the achievement of targeted outcomes followed by the Kern Six-step curriculum development model, namely: (1) problem identification and general need assessment; (2) targeted need assessment; (3) goals and objectives; (4) educational strategies; (5) implementation; and (6) evaluation and feedback. This resulted in four comprehensive modules and seventeen competencies throughout the fourteen-week EMD Program.

\section{Conclusion}

As part of the health sector transformation plan in KSA, EMD services play a fundamental role in the daily operations of prehospital healthcare services. Developing an EMD Program with a consecutive mixed approach including a competency-based with backward design method followed by the Kern Six-step curriculum development model led to a set of learning outcomes in the EMD Program including interpreting various dispatch systems, prioritizing incidents, deploying proper resources, and providing pre-arrival instructions to improve the current operations of EMD services, allow rapid access to healthcare facilities, and ultimately save more lives.

\section{Background}

Healthcare medical dispatch systems play a fundamental role in the daily operations of prehospital services. It allows the basic interpretation of various dispatch-related systems, receiving incident calls, categorizing cases, guiding proper resources deployment, and providing proper instructions before the arrival of healthcare providers. The scope of services extends to include interfacility transport, medivac missions, and certain overwhelming situations such as mass causality incidents. In light of the Kingdom of Saudi Arabia's (KSA's) health sector transformation plan as part of the Vision 2030, developing an Emergency Medical Dispatch (EMD) Program as part of the essential prehospital services will allow rapid and competent healthcare delivery [1]. In KSA, the Saudi Red Crescent Authority (SRCA) is the national provider of prehospital services and receives incidents via the unified number " 997 ", as the main source, along with others such as the public safety unified number "911" and certain electronic applications (Asafny and Tawakkalna) [2,3,4,5]. The dispatching process is subsequently facilitated by a dispatcher with prerequisite exposure to selected training courses including an Emergency Telecommunicator Course (ETC) and an EMD Course [6]. The triage, resources deployment, and pre-arrival instruction are applied according to local SRCA protocols. Nevertheless, to ensure rapid access to healthcare services efficiently dispatchers are required to fulfill specific competencies in EMD. Therefore, in light of the urgent demand for a competency-based program, the Health Academy (HA), affiliated with the Saudi Commission for Health Specialties (SCFHS), which specializes in health professional training in KSA, developed a novel curriculum named EMD Program as part of vocational training of health professions education [7].

The EMD Program fulfills an essential role in caring for patients in the prehospital field and is geared towards favorable outcomes based on the acquisition of foundational knowledge, skills, and attitudes.

This program prepares dispatchers to be a member of the healthcare system by providing rapid access to essential prehospital services efficiently and effectively. It will be used to meet the demand in the dispatch workforce for the nationalization of healthcare professions' roles and jobs in alignment with the KSA Vision 2030 and the health sector transformation plan [1].

In this study, we aim to describe the curriculum development of the EMD Program in KSA to improve the novel training of dispatchers and share our experience to allow better prehospital dispatch systems.

\section{Methods}

Due to the urgent demand for a comprehensive EMD Program in the region, as part of the national health sector transformation plan to improve access to prehospital services, the HA, in collaboration with the SRCA, recruited a group of education experts in EMS dispatch to develop the dispatch curriculum. Affiliated with SCFHS, the HA, located in Riyadh, Saudi Arabia, aims to improve training in the health sector by increasing the knowledge and effectiveness of the healthcare provider through well-structured training programs. The SRCA is the national provider of prehospital services in KSA with over 450 dispatchers 
in thirteen different dispatch centers, centrally monitored by the operations center at headquarters in Riyadh, Saudi Arabia. Experts from both entities included emergency medicine consultants (Prehospital and Medical Education Fellowships), senior paramedics (PhDs with more than 5 years' experience in EMD), and experts in health professions education and curriculum development who joined under the EMD education committee. Frequent focus group discussions of the twelve members of the committee were conducted over six months, in Riyadh, to discuss best dispatch practices and build a framework for the program curriculum, syllabus, logbook, and exam blueprint. The development of the EMD program utilized a consecutive mixed approach starting with a competencybased with backward design method followed by the Kern Six-step curriculum development model to ensure the achievement of targeted learning outcomes $[8,9]$. The backward design method led to four modules and seventeen competencies designed in a stepwise comprehensive approach that mandates trainees go through consecutively. First, introduction to EMD (Module one) targeting basic communication and ethics-related issues in the dispatch profession. Next, the basic interpretation of the dispatch system is addressed in Basic EMD Concepts (Module two). In EMD Response \& Management (Module three) trainees will learn how to approach a variety of incidents, categorize them, deploy proper services, and instruct callers in a certain fashion to respond properly (prearrival instructions). Finally, Crisis Management, Quality \& Legal Issues \& Coaching in EMD (Module four) contains advanced requirements in dealing with overwhelming resources, dispatch quality, medicolegal aspects, stress coping mechanisms, and how to coach others in the profession. The total contact hours are 40 hours for module 1, 40 hours for module 2, 120 hours for module 3, 200 hours for module 4, 120 hours for internship \& certifications, and 40 hours for the final exams. All competencies embedded in each module used Bloom's Taxonomy of Educational Objectives that embraces the domain of learning, namely (i) knowledge, (ii) psychomotor skills, and (iii) attitude as shown in Table 1 [10]. The Kern Six-step curriculum development model, the approved approach by the HA, SCFHS used nationally for medical and allied health programs guided the logical progression of the curriculum including: (1) problem identification and general need assessment; (2) targeted need assessment; (3) goals and objectives; (4) educational strategies; (5) implementation; and (6) evaluation and feedback [9]. The curriculum was subsequently reviewed by two independent expert external reviewers and feedback was addressed accordingly. Upon fulfillment, the EMD Program was uploaded to the HA platform for EMD Program trainees and interested individuals to access easily [11].

The main aim of this study is to describe the approach followed in the development of the newly developed EMD Program and ultimately standardize dispatch-related training programs. The data of this study was collected by reviewing approved documents of the EMD Program including program curriculum, syllabus, logbook, and exam blueprint after approval letters received from the HA, SCFHS.

\section{Results}

Upon writing this manuscript, the EMD Program training has not yet started and the first batch is expected to be enrolled in the program by the end of the year 2021. Trainees will be enrolled on a full-time, continuous basis for the entire fourteen-week duration of the EMD Program including examination weeks. After trainees complete graduation requirements, they will receive along with a certificate of graduation, a professional classification and registration as an EMD specialist by SCFHS and be licensed to work in dispatch centers in KSA. The admission criteria for applicants are detailed in Table 2 and were kept in mind when designing the curriculum based on the expected backroad competencies of the trainees [11]. All dropout, postponement, and withdrawal requests during the EMD Program will follow HA guidelines and a service request should be applied accordingly [12]. After written notification of acceptance into the EMD Program, the trainees responsibilities and rights will apply before and during the clinical experience as shown in Table 2.

\section{Problem Identification and General Needs Assessment}

The EMD system is growing in the healthcare sector and more functions are added constantly. Receiving emergency calls requires achieving competencies in knowledge, skills, and attitudes to enable the categorization of cases and the deployment of proper resources. Globally, a variety of dispatch systems exist and are built based on local demand, type of incidents, and terrain differences leading to a complex of operation services, hence standardizing international dispatch policies and procedures is impractical. Moreover, Emergency Medical Dispatchers (EMDs) are from different backgrounds and experiences and receive a variety of training programs to develop and maintain their fundamental dispatching skills throughout their career, adding more to the challenge of unifying dispatch language.

In KSA, EMDs receive vigorous dispatch-related training programs set by the SRCA to maintain daily operation services in EMD.

However, no dispatch program with targeted competencies and learning objectives according to which dispatcher trainees can be assessed regularly, currently exists. Building an EMD Program with a recognized SCFHS classification, in alignment with the national health sector transformation plan, would improve access to prehospital services through efficient and effective dispatch services and develop a clear career pathway for EMDs in KSA.

\section{Targeted Needs Assessment}

An international benchmarking of many EMD systems, curriculum, programs, and courses was set by the committee after reviewing several EMD books, relevant training manuals, and related scientific papers. This included: (1) National Emergency Communication Institute-USA (EMD National Certification Course); (2) National Highway Traffic Safety Administration-USA (NHTSA) (NHTSA EMD National Standard Curriculum); (3) the Association of Public Safety Communications Officials International; (4) Seneca College-Canada (911 \& Emergency Services Communications); (5) the Principles of Emergency Medical Dispatch textbook 6th edition; and (6) many others $[13,14,15,16,17,18,19,20,21,22,23,24,25,26,27,28,29,30,31,32,33]$. Locally, the committee evaluated current dispatch systems, met with employees and experts in the field, and collected feedback evaluations from the local dispatch community, to set a group of learning outcomes covering the three learning domains knowledge, skills, and attitudes. The proposed targeted needs, therefore, were set to contain competencies in professionalism and communication, basic knowledge, and skills in interpreting various dispatch systems, prioritizing emergency calls, providing pre-arrival instruction, and dealing with special situations in EMD classified into four modules as shown in Table 1.

\section{Goals and Objectives}


The goal of the EMD Program is to improve the integration of current dispatch systems and unify the dispatch language as part of the national health sector transformation plan and Vision 2030 to accelerate the provision of efficient prehospital services and reinforce the role of the EMDs in receiving emergency and non-emergency calls, the dispatch of ambulances to the sites required according to the medical protocol, coordination with the concerned authorities, and directing callers on how to deal with emergency and non-emergency cases. The EMD Program objectives were identified and matched with competencies followed by further elaboration of specific learning outcomes for each module to guide the educational process and Bloom's Taxonomy of Educational Objectives was used as shown in Table 3 [10].

\section{Educational Strategies}

E-learning and simulation-based learning activities are evolving in health professions education and are being adopted to test different dispatch skills along with the program. In a well-equipped simulation environment (simulation lab), trainees will be exposed to a variety of pre-recorded scenarios to measure each competency by specialized expert simulation educators. A debriefing discussion after each session will take place to highlight passing points, lessons learned, and areas for improvement in every case. To ensure effective educational strategies and achieve educational objectives of the EMD Program, Kolb's two levels experimental learning theory (four-stage cycle and four separate learning styles) was adopted [34]. The experimental learning cycle includes: Concrete Experience (CE) (feeling); Reflective Observation (RO) (watching); Abstract Conceptualization (AC) (thinking); and Active Experimentation (AE) (doing). In his theory, learning styles are usually a product of two learning variables that include: Diverging (CE+RO); Assimilating (AC+RO); Converging (AC+AE); and Accommodating $(\mathrm{CE}+\mathrm{AE})$. He further elaborates in his matrix, the two continuum east-west axis also called Processing Continuum (how we approach a task by watching or doing) and the north-south axis also known as Perception Continuum (our emotional response to a task, or how we think or feel) and he believed that only one variable on a single axis can be achieved at a time. Based on that, a set of educational strategies were identified to be the most appropriate educational methods to achieve the desired learning outcomes in the EMD Program. A detailed tentative schedule and educational strategies of the program are illustrated in Table 4.

\section{Implementation}

Considering KSA Vision 2030 and the health sector transformation plan, implementing this program on a national level would ease access to healthcare systems, provide efficient and effective prehospital services, and allow the integration of existing EMD systems in the country. The use of Kolb's theory was crucial to implement the program's educational strategies and achieve educational objectives [34]. Moreover, to implement this program, a set of formal proposals by higher authorities concerned with prehospital healthcare services and medical education for healthcare providers approved the launch and sponsorship of the program [2,7]. Nevertheless, setting specific criteria for faculty requirements and training sites was crucial for the program's implantation [11]. Having said that, the achievement of the desired learning outcomes of the EMD Program was facilitated by many elements. First, the national intention to transform the health sector and ease access to services was the driving energy to build this program. Second, the curriculum was developed by an experienced educational committee in the field of prehospital service, EMD systems, medical education, and curriculum development. This committee had specified the required personnel, time, facilities, and funding resources needed to develop this program. Finally, the partnership with SRCA, the national provider of prehospital services, empowered the implementation of the program outcomes in the actual dispatch operations services.

\section{Evaluation and Feedback}

The curriculum evaluation and feedback will be collected by the HA from different stakeholders (students, faculty, training sites) periodically by filling in electronic surveys for ongoing quality improvements during the program implementation and screening for rapidly reversible corrections related to curriculum faculty and training centers. By the end of the program, a comprehensive survey will be distributed among all stakeholders to revise and update any changes related to the curriculum content, modes of delivery, training facilities, tutors' performance, and suggestions for further improvement in the program by a curriculum review committee. As part of the curriculum development of the EMD Program, trainees are evaluated constantly by formative and summative assessments to ensure the targeted learning outcomes are achieved [35]. Overall, the assessment and evaluation of trainees are carried out in alignment with the SCFHS training and examination rules and regulations. This included every aspect of the trainee's performance, whether in classrooms, simulation labs, or dispatch operations center. For each module, the assessment process enables those involved in the training process (i.e., faculty) to provide objective feedback to the trainees periodically (every month). For each module, the grading system will be $20 \%$ for attendance and punctuality, $40 \%$ for ongoing formative assessment (quizzes, presentations, or group activities), and $40 \%$ for the summative assessment (end of module exam). The final written exam (summative assessment) will be conducted centrally by the SCFHS, covering a detailed exam blueprint that is mapped to the competencies across all program modules. Exam format shall consist of no more than 120 multiple choice questions with a single best answer (one correct answer out of four options) covering basic concepts and clinical topics relevant to the EMD. The distribution of grades in the exam blueprint is different depending on formative and summative assessment, Kolb's educational strategies, competency-based aspects, and various distribution of knowledge, skill, and attitude percentages in each module as shown in Table 4.

To obtain an EMD Program certificate, the trainee must fulfill the following requirements: successful completion of all modules, successful completion of the internship period, attendance: total absence percentage during the program is $10 \%$ or less, passing the final examination with no less than $60 \%$, passing the Objective Structured Clinical Examination or Structured Oral Exam with no less than 60\%, and passing the ETC and EMD courses.

\section{Discussion}

To our knowledge, this is one of the first structured EMD Programs in Saudi Arabia. This program will serve the prehospital EMS system by developing the knowledge and skills of dispatchers, so they can respond to incident calls efficiently, deploy proper services and resources, and provide proper lifesaving instructions, as envisaged in the national health sector transformation plan and Vision 2030. In the EMD Program, modules discuss essential communication skills and how to act professionally in the EMD field, interpretations of a dispatch system, dispatch coding and deployment of proper resources, knowledge of 
common medical emergencies, applying dispatch life support services, and addressing certain aspects of EMD (crises management, quality management, legal issues, coping with stressors, coaching skills). The development of the EMD program utilized a consecutive mixed approach starting with a competencybased with backward design method to ensure the achievement of targeted outcomes [8]. This was followed by the adoption of Kern's Six-step approach for structure content and integrated module development which has proven efficacy in many education settings $[9,36,37,38,39,40]$. The EMD Program targeted learning objectives were then developed by the education committee and Miller's pyramid of competencies was considered following its successful use in recent programs [41]. The impact of the EMD Program will strongly affect the prehospital dispatch system in KSA as we recommend that other dispatch training programs adopt the suggested curriculum to validate its efficacy and perhaps adopt outcomes for their related dispatch systems. Furthermore, designing a career pathway for EMDs by recognizing the graduation certificate and granting a dispatcher license recognized by authorities will attract more dispatchers to join the EMD community and seek it as a career.

The curriculum developed by the HA is approved for implementation as part of a greater timeline for healthcare transformation in KSA. Consequent monitoring of the implementation will measure the impact that will feedback into curriculum improvement and overall evaluation of the medical dispatch system. Further studies are recommended to measure outcomes and effectiveness concurrent to international benchmarking of results.

\section{Conclusion}

As part of the health sector transformation plan in KSA, EMD services play a fundamental role in the daily operations of prehospital healthcare services. Developing an EMD Program with a consecutive mixed approach including a competency-based with backward design method followed by the Kern Six-step curriculum development model led to a set of learning outcomes in the EMD Program including interpreting various dispatch systems, prioritizing incidents, deploying proper resources, and providing pre-arrival instructions to improve the current operations of EMD services, allow rapid access to healthcare facilities, and ultimately save more lives.

\section{Declarations}

\section{Ethics approval and consent to participate}

Not applicable as there is no data collection, interaction, or intervention with any human subject in this study.

\section{Consent for publication}

HA, SCFHS agreed to share with the authors the final approved documents of the EMD Program including the program curriculum, syllabus, logbook, exam blueprint, and minutes of the meeting of the education committee of the EMD Program after signing a non-disclosure agreement.

\section{Availability of data and materials}

The data referred to in this study are available from HA, SCFHS but restrictions apply to the availability of these data, which were used under license for the current study, and can be released by justified written request to the relevant authorities. Data for verification of scientific purposes are however available from the authors upon request with permission of HA, SCFHS.

\section{Competing interests}

Not applicable.

\section{Funding}

Not applicable.

\section{Authors' contributions}

YM, NA, AC, WA, S Alharthi developed the study design. KA and MA analyzed and interpreted the study data. AA and AS mapped study results on a structural framework. YM wrote the manuscript, FA, JA, BM, S Alsolamy, and AS were heavily involved in the editing. All authors read and approved the final manuscript.

\section{Acknowledgment}

We would like to thank the Health Academy of the Saudi Commission for Health Specialties, the Saudi Red Crescent Authority, and the education committee of the Emergency Medical Dispatch Program for their support in writing this paper. Professor Mustafa Bodrick, Adjunct Faculty at King Saud University, is acknowledged for the final review and related improvements of this manuscript.

\section{References}

1. Kingdom of Saudi Arabi's Vision 2030. Health Sector Transformation Program. https://www.vision2030.gov.sa/v2030/vrps/hstp/. Accessed 23 Oct 2021.

2. Saudi Red Crescent Authority. About. https://www.srca.org.sa/en. Accessed 2 Nov 2021.

3. Althumairi A, Alnasser Z, Alsadeq S, Al-Kahtani N, Aljaffary A. Mobile Ambulatory Application Asafny and Traditional Phone Request 997: A Comparative Cross-Sectional Study. Open Access Emerg. Med; 2020. 12: 471-80. https://doi.org/10.2147/OAEM.S279969 
4. ARAB NEWS. Saudi Red Crescent joins Interior Ministry's 911 services. 2019. https://www.arabnews.com/node/1524491/saudi-arabia. Accessed 7 Nov 2021.

5. Saudi Gazette. Tawakkalna's update includes new Hajj, SOS services. 2021. https://saudigazette.com.sa/article/608081/SAUDI-ARABIA/Tawakkalnasupdate-includes-new-Hajj-SOS-services. Accessed 25 Oct 2021.

6. International Academies of Emergency Dispatch. Certification Courses. https://www.emergencydispatch.org/what-we-do/courses-and-training? tab=medical-tab. Accessed 22 Oct 2021.

7. Saudi Commission for Health Specialties. Health Academy. https://ha.edu.sa/careers. Accessed 24 Oct 2021.

8. Alsolamy S, Cluntun A, Aldekhyl S, Sabbagh AY, Alshehri TO, Yousif S, Abuznadah WT, Alharthi S, Alshamrani A, Bodrick MM. A National Initiative: Training Nonintensivists in Critical Care, an Educational Response to the COVID-19 Pandemic. Saudi Crit. Care J. 2020 Dec 1;4(5):34.

https://doi.org/10.4103/sccj.sccj_50_20.

9. Thomas PA, Kern DE, Hughes MT, Chen BY, editors. Curriculum development for medical education: a six-step approach. JHU Press; 2016 Jan 29. https://books.google.com.sa/books?

$\mathrm{hl}=$ en\&lr=\&id=UxF4CWAAQBAJ\&oi=fnd\&pg=PP1\&dq=Thomas+PA,+Kern+DE,+Hughes+MT,+Chen+BY,+editors.+Curriculum+development+for+medical+ed step+approach.+JHU+Press\%3B+2016+Jan+29.\&ots=1fMzWTK_Gx\&sig=TOKYgfQkkzunSyCOPkaZCd3HHAo\&redir_esc=y\#v=onepage\&q\&f=false. Accessed 7 Nov 2021.

10. Krathwohl DR. A Revision of Bloom's Taxonomy: An Overview. Theory Pract. 2002;41(4):212-18. https://doi.org/10.1207/s15430421tip4104_2.

11. Health Academy. EMD Program. https://ha.edu.sa/emergency-medical-dispatcher. Accessed 5 Nov 2021.

12. Saudi Commission for Health Specialties. Postponement/ Dropout/ Withdrawal Services. https://www.scfhs.org.sa/en/MESPS/Pages/-PostponementTermination-Withdrawal-Services-.aspx. Accessed 17 Oct 2021.

13. National Emergency Communications Institute. Basic 9-1-1 Certification Course. https://neci911.com/individual-course-description/. Accessed 13 Oct 2021.

14. ERIC. Emergency Medical Dispatch. National Standard Curriculum. Instructor Guide. Trainee Guide. https://eric.ed.gov/?id=ED425308. Accessed 14 Oct 2021.

15. APCO International. About. https://www.apcointl.org/. Accessed 12 Oct 2021.

16. Seneca. 911 \& Emergency Services Communications. https://www.senecacollege.ca/programs/fulltime/ESC.html. Accessed 13 Oct 2021.

17. Priority Dispatch. Principles of Emergency Medical Dispatch textbook. https://prioritydispatch.net/support_products/. Accessed 10 Oct 2021.

18. McKenna K, Sanders M. Mosby's Paramedic Textbook 4th edition. Elsevier; 2011. https://www.elsevier.com/books/mosbys-paramedictextbook/unknown/978-0-323-07275-5. Accessed 22 Oct 2021.

19. Belmont Police Department. Dispatcher Training Program. 2019. https://www.belmont.gov/home/showpublisheddocument/19021/637135636345570000. Accessed 23 Oct 2021.

20. Alameda Police Department. Public Safety Dispatcher Training Manual. 2019.

https://www.alamedaca.gov/files/assets/public/departments/alameda/police/comcen-training-manual.pdf. Accessed 23 Oct 2021.

21. Saudi Commission for Health Specialties. Professionalism and Ethics Handbook for Residents. 2015.

https://www.scfhs.org.sa/en/Media/OtherPublications/Documents/Professionalism\%20and\%20Ethics\%20Handbook\%20for\%20Residents.pdf. Accessed 26 Oct 2021.

22. Saudi Commission for Health Specialties. Communication Skills. 2016. https://www.scfhs.org.sa/Media/DigitalLibrary/DocumentLibrary/OtherPublications/Documents/Communication\%20Skills.pdf. Accessed 26 Oct 2021.

23. Fry S, Johnstone MJ. Ethics in Nursing Practice: A Guide to Ethical Decision Making, 3rd Edition. Wiley; 2008. https://www.wiley.com/enam/Ethics+in+Nursing+Practice\%3A+A+Guide+to+Ethical+Decision+Making\%2C+3rd+Edition-p-9781405160520. Accessed 23 Oct 2021.

24. Cone D, Brice JH, Delbridge TR, Myers B. Emergency Medical Services: Clinical Practice and Systems Oversight, 2 Volume Set, 3rd Edition. Wiley; 2021. https://www.wiley.com/en-us/Emergency+Medical+Services\%3A+Clinical+Practice+and+Systems+Oversight\%2C+2+Volume+Set\%2C+3rd+Edition-p9781119756248. Accessed 25 Oct 2021.

25. National Highway Traffic Safety Administration Office of Emergency Medical Services (EMS). Emergency Communications Centers and the Role of Communications Technologies in Reducing Mortality Rates in the Rural U.S. 2016. https://www.ems.gov/pdf/advancing-ems-systems/Reports-andResources/ECC-Role-of-Communications-Technologies.pdf. Accessed 26 Oct 2021.

26. Larribau R, Chappuis VN, Cottet P, Regard S, Deham H, Guiche F, Sarasin FP, Niquille M. Symptom-Based Dispatching in an Emergency Medical Communication Centre: Sensitivity, Specificity, and the Area under the ROC Curve. Int. J. Environ. Res. Public Health. 2020 Jan;17(21):8254. https://doi.org/10.3390/ijerph17218254.

27. Fales W. Fundamentals of EMS dispatch. National Association of EMS Physicians. https://naemsp.org/NAEMSP/media/NAEMSPDocuments/Annual\%20Meeting/MDC\%20references-multi-year/MDC-REF-EMS-Radios-for-EMS-and-Disaster-Communications.pdf. Accessed 27 Oct 2021.

28. Ismail AK, Yun YY, Mahardhika G, Ghani AA, Ahmad NS, Mustafa AK, Jamal SM, Nordin R, Zainal N. The Effectiveness of a Navigation System for Ambulance Service in Kuala Lumpur, Malaysia. Malaysian J.Public Health Med. 2018;(1) 166-173. https://www.researchgate.net/profile/Ahmad-KhaldunIsmail/publication/324441823_The_effectiveness_of_a_navigation_system_for_ambulance_service_in_Kuala_Lumpur_Malaysia/links/5b55ff160f7e9b24 effectiveness-of-a-navigation-system-for-ambulance-service-in-Kuala-Lumpur-Malaysia.pdf. Accessed 27 Oct 2021. 
29. Jacobson CL, Basnet S, Bhatt A, Parajuli S, Shrestha SK. Emergency medical dispatcher training as a strategy to improve pre-hospital care in low-and middle-income countries: the case study of Nepal. Int J Emerg Med. 2021 Dec;14(1):1-7. https://doi.org/10.1186/s12245-021-00355-8.

30. EM Resident. Emergency Medical Dispatch: The True First Responder. 2020. https://www.emra.org/emresident/article/em-dispatch/. Accessed 28 Oct 2021.

31. Golding SE, Horsfield C, Davies A, Egan B, Jones M, Raleigh M, Schofield P, Squires A, Start K, Quinn T, Cropley M. Exploring the psychological health of emergency dispatch centre operatives: a systematic review and narrative synthesis. PeerJ. 2017 Oct 17;5:e3735. https://doi.org/10.7717/peerj.3735

32. Saudi Commission for Health Specialties. Health Leadership Academy Services. https://www.scfhs.org.sa/en/eservices/Pages/HLA.aspx. Accessed 28 Oct 2021.

33. CV Nieuwerburgh. An introduction to coaching skills: A practical guide second edition. Sage; 2020 Aug 24. https://www.amazon.com/IntroductionCoaching-Skills-Practical-Guide/dp/1473975816. Accessed 28 Oct 2021.

34. McLeod SA. Simply Psychology. Kolb - learning styles. 2017. . Accessed 6 Nov 2021.

35. Zook C. Applied educational systems. Formative vs. Summative Assessments: What's the Difference? 2017. https://www.aeseducation.com/blog/formative-vs.-summative-assessments-what-do-they-mean. Accessed 2 Nov 2021.

36. Sweet LR, Palazzi DL. Application of Kern's Six-step approach to curriculum development by global health residents. Educ Health. 2015 May 1;28(2):138. https://doi.org/10.4103/1357-6283.170124.

37. Pietersen $\mathrm{PI}$, Laursen $\mathrm{CB}$, Petersen RH, Konge L. Structured and evidence-based training of technical skills in respiratory medicine and thoracic surgery. J of Thorac Dis. 2021 Mar;13(3):2058. https://doi.org/10.21037/jtd.2019.02.39.

38. Martin SK, Ahn J, Farnan JM, Fromme HB. Introduction to curriculum development and medical education scholarship for resident trainees: a webinar series. MedEdPORTAL. 2016 Sep 16;12. https://doi.org/10.15766/mep_2374-8265.10454

39. Robertson AC, Fowler LC, Niconchuk J, Kreger M, Rickerson E, Sadovnikoff N, Hepner DL, Bader AM, Mcevoy MD, Urman RD. Application of Kern's 6-Step Approach in the Development of a Novel Anesthesiology Curriculum for Perioperative Code Status and Goals of Care Discussions. J Educ Perioper Med. 2019 Jan;21(1). PMID: 31406705. PMCID: PMC6685461.

40. Al-Ghamdi HS. A novel approach to teaching dermatology and plastic surgery in a combined module for undergraduate medical students. Adv Med Educ Pract. 2019;10:147. https://doi.org/10.2147/AMEP.S191931

41. Munzer T, Roller-Wirnsberger R, Van Den Noortgate N, Bonin-Guillaume S, Andersen-Ranberg K, Hylen Ranhoff A, et al. Setting competencies and standards for a European Leadership Program in Geriatric Medicine: "The European Academy for Medicine of Ageing (EAMA) reloaded". Eur Geriatr Med. 2018;9:399-406. https://doi.org/10.1007/s41999-018-0052-4.

\section{Tables}


Table 1

Modules and Competencies of EMD Program

\begin{tabular}{|c|c|c|c|c|}
\hline Module & Competencies & Knowledge & Skill & Attitude \\
\hline \multirow{3}{*}{$\begin{array}{l}\text { Module } 1 \\
\text { Introduction to EMD }\end{array}$} & $\begin{array}{l}\text { Act professionally and ethically in a capacity as an emergency medical } \\
\text { dispatcher }\end{array}$ & $\checkmark$ & & $\checkmark$ \\
\hline & Demonstrate roles and responsibilities of the emergency medical dispatcher & $\checkmark$ & & \\
\hline & $\begin{array}{l}\text { Recognize the basics of telecommunication skills for emergency and non- } \\
\text { emergency cases }\end{array}$ & $\checkmark$ & $\checkmark$ & \\
\hline \multirow{3}{*}{$\begin{array}{l}\text { Module } 2 \\
\text { Basic EMD Concepts }\end{array}$} & Outline the basics of emergency telecommunication technologies & $\checkmark$ & $\checkmark$ & \\
\hline & Interpret data from Geographical Information System / Mapping systems & $\checkmark$ & $\checkmark$ & \\
\hline & Interpret computer-aided dispatch system & $\checkmark$ & $\checkmark$ & \\
\hline \multirow{6}{*}{$\begin{array}{l}\text { Module } 3 \\
\text { EMD Response \& Management }\end{array}$} & $\begin{array}{l}\text { Describe the basics of anatomy and physiology of the human body as it } \\
\text { pertains to emergency medical dispatcher practice }\end{array}$ & $\checkmark$ & & \\
\hline & Organize dispatch coding system on emergency and non-emergency cases & $\checkmark$ & $\checkmark$ & \\
\hline & Apply dispatch life support services & $\checkmark$ & $\checkmark$ & \\
\hline & Describe call instruction management techniques for various scenarios & $\checkmark$ & $\checkmark$ & \\
\hline & Make use of the caller management techniques & $\checkmark$ & & $\checkmark$ \\
\hline & $\begin{array}{l}\text { Define common medical and traumatic emergencies in emergency medical } \\
\text { dispatch }\end{array}$ & $\checkmark$ & $\checkmark$ & \\
\hline \multirow{5}{*}{$\begin{array}{l}\text { Module } 4 \\
\text { Crisis Management, Quality \& Legal } \\
\text { Issues \& Coaching in EMD }\end{array}$} & Evaluate crises and emergency management in emergency medical dispatch & $\checkmark$ & $\checkmark$ & \\
\hline & Utilize quality management in emergency medical dispatch & $\checkmark$ & $\checkmark$ & \\
\hline & $\begin{array}{l}\text { Identify essential legal aspects and security situations in emergency medical } \\
\text { dispatch }\end{array}$ & $\checkmark$ & $\checkmark$ & $\checkmark$ \\
\hline & Analyze stressors in the emergency medical dispatch profession & $\checkmark$ & $\checkmark$ & $\checkmark$ \\
\hline & Practice coaching in emergency medical dispatch & $\checkmark$ & $\checkmark$ & $\checkmark$ \\
\hline
\end{tabular}


Table 2

EMD Program Admission Criteria, Trainees Responsibilities, and Rights

\begin{tabular}{|c|c|}
\hline \multicolumn{2}{|c|}{ Admission Criteria } \\
\hline Qualification & Bachelor's degree in Health Administration or its equivalent \\
\hline Licenses & Valid SCFHS medical license in Health Administration \\
\hline Certification & Active Basic Life Support Certificate \\
\hline Health status & Good health \\
\hline Skills & Adequate computer skills \\
\hline $\begin{array}{l}\text { English } \\
\text { language } \\
\text { proficiency }\end{array}$ & $\begin{array}{l}\text { Proof of English exam with total International English Language Testing System score not less than } 4.5, \text { or Test of English as a } \\
\text { Foreign Language total score of 32-34 minimum }\end{array}$ \\
\hline \multicolumn{2}{|c|}{ Trainees Responsibilities } \\
\hline \multirow{3}{*}{$\begin{array}{l}\text { Before the EMD } \\
\text { Program }\end{array}$} & Purchase required uniforms and required equipment \\
\hline & Provide health requirements according to the institution's regulations \\
\hline & Arrange and plan transportation needs to avoid absenteeism \\
\hline \multirow[t]{2}{*}{$\begin{array}{l}\text { During the EMD } \\
\text { Program }\end{array}$} & $\begin{array}{l}\text { Are expected to wear the required uniform and adhere to all clinical settings rules and regulations as inappropriate behaviors and } \\
\text { offensive remarks will not be tolerated in the program }\end{array}$ \\
\hline & $\begin{array}{l}\text { Must notify their clinical instructor, or faculty member regarding any absences (emergencies, absence from classes, and clinical } \\
\text { settings) as any unexcused absences may result in non-admission to examinations }\end{array}$ \\
\hline \multicolumn{2}{|l|}{ Trainees Rights } \\
\hline \multicolumn{2}{|c|}{ Introduced to the program and have clear roles and objectives described } \\
\hline \multicolumn{2}{|c|}{ Receive orientation on the educational material and training sites } \\
\hline \multicolumn{2}{|c|}{ Trained in fundamental aspects of EMD } \\
\hline \multicolumn{2}{|c|}{ Access dispatch operation centers to gain required knowledge and skills } \\
\hline \multicolumn{2}{|c|}{ Allowed to take authorized breaks } \\
\hline Provided with reg & ar constructive feedback \\
\hline
\end{tabular}

Table 3

Goals and Objectives of EMD Program

\begin{tabular}{|l|}
\hline Goals and Objectives \\
\hline Illustrate proper communications skills and professionalism \\
Describe basic telecommunication skills \\
Interpret dispatch-related systems \\
Prioritize incidents categories \\
Explain common medical emergencies \\
Provide pre-arrival instructions \\
Recognize occupational stress and coping mechanism \\
Identify quality improvement projects \\
Recognize major legal issues \\
Coach others in emergency medical dispatch
\end{tabular}




\begin{tabular}{|c|c|c|c|c|c|}
\hline Week & Module & Topics & Educational Strategies & $\begin{array}{l}\text { Clinical } \\
\text { Rotation } \\
\text { (EMD Center) } \\
\text { per week }\end{array}$ & $\begin{array}{l}\text { Module } \\
\text { Exam } \\
\text { Percentage }\end{array}$ \\
\hline 1 & $\begin{array}{l}\text { Module } \\
1\end{array}$ & $\begin{array}{l}\text { - Introduction to EMD Program } \\
\text { - Essential basics of ethics \& communication skills } \\
\text { - EMD professionalism attributes } \\
\text { - Impact of EMD on health system } \\
\text { - Profiles of EMD duties } \\
\text { - Misconceptions in EMD } \\
\text { - Partnership in EMD }\end{array}$ & $\begin{array}{l}\cdot \text { Group discussion } \\
\text { - Reading assignments } \\
\text { - Simulation with debriefing and } \\
\text { discussion } \\
\text { - Review \& summary of the week }\end{array}$ & $\begin{array}{l}1 \text { day } \\
\text { (orientation) }\end{array}$ & $10 \%$ \\
\hline 2 & $\begin{array}{l}\text { Module } \\
2\end{array}$ & $\begin{array}{l}\cdot \text { Basic Model of Communication in EMD } \\
\cdot \text { Techniques in telecommunications } \\
\text { - Role of telecommunications in EMD } \\
\text { - Key steps of the EMD call process } \\
\text { - Quantity \& quality care in EMD } \\
\text { - Approach to callers \& EMD protocols } \\
\text { - Handing over the dispatch message } \\
\text { - Dispatch diagnostic tools } \\
\text { - Interpreting Geographical Information System / Mapping } \\
\text { system } \\
\text { - Interpret computer-aided dispatch system }\end{array}$ & $\begin{array}{l}\text { - Simulation with debriefing and } \\
\text { discussion } \\
\text { - Videos } \\
\text { - Images } \\
\text { - Educational games } \\
\text { - Review \& summary of the week }\end{array}$ & 2 days & $30 \%$ \\
\hline 3 & $\begin{array}{l}\text { Module } \\
3\end{array}$ & $\begin{array}{l}\text { - Surface anatomy and physiology in EMD } \\
\text { - Transfer and vectoring in traumatic events } \\
\text { - Basic pathological concepts leading to medical } \\
\text { emergencies } \\
\text { - Dispatch coding system } \\
\text { - Dispatch life support }\end{array}$ & $\begin{array}{l}\text { - Simulation with debriefing and } \\
\text { discussion } \\
\text { - Group discussion } \\
\text { - Videos } \\
\text { - Images } \\
\text { - Medical dictionaries } \\
\text { - Educational games } \\
\text { - Reading assignments } \\
\text { - Review \& summary of the week }\end{array}$ & 2 days & $40 \%$ \\
\hline 4 & & $\begin{array}{l}\text { - Post-dispatch \& pre-arrival instructions } \\
\text { - Caller management techniques }\end{array}$ & $\begin{array}{l}\text { - Simulation with debriefing and } \\
\text { discussion } \\
\text { - Reading assignments } \\
\text { - Videos } \\
\text { - Educational games } \\
\text { - Case discussion }\end{array}$ & 3 days & \\
\hline 5 & & $\begin{array}{l}\text { - Common medical emergencies } \\
\text { - Common traumatic emergencies }\end{array}$ & $\begin{array}{l}\text { - Simulation with debriefing and } \\
\text { discussion } \\
\text { - Reading assignments }\end{array}$ & 2 days & \\
\hline 6 & $\begin{array}{l}\text { Module } \\
4\end{array}$ & Crises and emergency management in EMD & $\begin{array}{l}\text { - Simulation with debriefing and } \\
\text { discussion } \\
\text { - Videos } \\
\text { - Educational games }\end{array}$ & 3 days & $20 \%$ \\
\hline
\end{tabular}




\begin{tabular}{|c|c|c|c|c|c|}
\hline Week & Module & Topics & Educational Strategies & $\begin{array}{l}\text { Clinical } \\
\text { Rotation } \\
\text { (EMD Center) } \\
\text { per week }\end{array}$ & $\begin{array}{l}\text { Module } \\
\text { Exam } \\
\text { Percentage }\end{array}$ \\
\hline 7 & & Quality management in EMD & $\begin{array}{l}\text { - Group discussion } \\
\text { - Simulation with debriefing and } \\
\text { discussion }\end{array}$ & 3 days & \\
\hline 8 & & Essential legal aspects in EMD & Case discussion & 3 days & \\
\hline 9 & & Stressors in the EMD profession & Group discussion & 3 days & \\
\hline 10 & & Coaching in EMD & $\begin{array}{l}\text { - Group discussion } \\
\text { - Educational games } \\
\text { - Simulation with debriefing and } \\
\text { discussion }\end{array}$ & 3 days & \\
\hline $\begin{array}{l}11 \\
12 \\
13\end{array}$ & \multicolumn{2}{|c|}{$\begin{array}{l}\text { Internship \& certifications }{ }^{*} \\
\text { (Clinical skills demonstrations) }\end{array}$} & & & \\
\hline 14 & Final ex & ninations & & & \\
\hline
\end{tabular}

